\title{
Commonly used medications and endometrial cancer survival: a population-based cohort study
}

\author{
Omolara B Sanni ${ }^{*}, 1$, Úna C Mc Menamin ${ }^{1}$, Chris R Cardwell ${ }^{1}$, Linda Sharp ${ }^{2}$, Liam J Murray ${ }^{1}$ \\ and Helen G Coleman ${ }^{1}$ \\ ${ }^{1}$ Cancer Epidemiology and Health Services Research Group, Centre for Public Health, Royal Victoria Hospital, Queen's University \\ Belfast, Block B, Grosvenor Road, Belfast, Northern Ireland and ${ }^{2}$ Institute of Health and Society, Newcastle University, Baddiley- \\ Clark Building, Richardson Road, Newcastle upon Tyne NE2 4AX, UK
}

Background: Increasing incidence and new indications for existing drugs make it important to identify new adjuvant therapies for endometrial cancer (EC).

\begin{abstract}
Methods: This is a prospective cohort study of 3058 newly diagnosed EC cases from 1998 to 2010, identified through record linkages between the UK Clinical Practice Research Datalink, the National Cancer Research Datalink and death registrations from the Office of National Statistics. Using Cox regression models, unadjusted and adjusted hazard ratios (HRs) and $95 \%$ confidence intervals (Cls) were calculated for EC-specific survival.
\end{abstract}

Results: Over a mean 6.1 (range 1-16) years of follow-up, there were 394 EC-specific deaths. There was no evidence of a significant association between post-diagnostic use of statins (adjusted HR 0.83, 95\% Cl 0.64, 1.08), $\beta$-blockers (adjusted HR 0.86 , $95 \% \mathrm{Cl} 0.65,1.13$ ) or low-dose aspirin (adjusted $\mathrm{HR} 0.91,95 \% \mathrm{Cl} 0.69,1.20$ ) and EC survival before or after adjustment for confounders. There were also no evidence of a dose-response association between these drug groups and EC survival.

Conclusions: In this large UK population-based study, no significant associations were observed for post-diagnostic use of statins, $\beta$-blockers or low-dose aspirin and EC survival.

Endometrial cancer (EC) is the fifth most common malignancy among women worldwide (Ferlay et al, 2015). There were $\sim 320000$ new cases diagnosed in 2012 and its incidence is projected to increase to around half a million by the year 2035 (Ferlay et al, 2015). The risk of developing EC is significantly increased in women with prolonged or excessive exposure to oestrogen (Dossus et al, 2010). Most cases of ECs are diagnosed at an early stage (Morice et al, 2016) and 5-year overall survival is relatively high, ranging from 74 to $91 \%$ in stages I or II but this falls to $20-26 \%$ in stage IV disease (Siegel et al, 2015). The majority of EC cases undergo hysterectomy (Morice et al, 2016) and although 5 -year survival rates are relatively good, there is room for improvement and in particular, identification of additional adjuvant treatments.

In recent years, new indications have been found for existing drugs in the process commonly referred to as drug repositioning, redirecting, reprofiling or repurposing (Gupta et al, 2013). Research has shown that some commonly prescribed medications that were originally indicated for other conditions may offer beneficial effects in terms of risk reduction and improved survival for different types of cancers (Gao et al, 2004, Cardwell et al, 2013, Lavie et al, 2013).

Three such classifications of drugs that have shown particular promise for potential adjuvant therapies for cancer are statins,

*Correspondence: OB Sanni; E-mail: osanni01@qub.ac.uk

Received 25 January 2017; revised 22 May 2017; accepted 9 June 2017; published online 6 July 2017

(C) 2017 Cancer Research UK. All rights reserved 0007-0920/17 
aspirin and $\beta$-blockers. Statins are inhibitors of 3-hydroxy-3methylglutaryl coenzyme A reductase and are primarily used as a cholesterol-lowering medication (Rutishauser, 2011). Statins have also been shown to have anti-proliferative and pro-apoptotic effects (Thibault et al, 1996). Recently, simvastatin was demonstrated to have significant anti-proliferative and anti-metastatic effects in EC cells (Schointuch et al, 2014). This suggests that statins may be useful in improving prognosis for EC patients. Earlier epidemiological studies have reported conflicting results for statin use in relation to survival among EC patients. One small Israeli study of 274 incident gynaecological cancers reported a $65 \%$ reduced risk of all-cause mortality (Lavie et al, 2013). This study included only a small sample of cases from a single institution and medication use was not treated as a time-dependent variable, which created a potential for immortal time bias. Another retrospective cohort study, which included 985 EC cases conducted in the United States, reported better disease-specific survival (Nevadunsky et al, 2015) among users of statins compared with non-users. This study also featured patients from a single institution and medication use was assessed at time of diagnosis only. In contrast, another retrospective cohort study of 2987 endometrial cases who received a hysterectomy within 6 months of diagnosis and survived at least 90 days after surgery, found no significant association between statin use and overall survival (Yoon et al, 2015).

$\beta$-Blockers, which are commonly prescribed for management of heart disease and hypertension (Aronow, 2010), have been suggested to have a role in the reduction of tumour occurrence, metastasis and cancer-specific mortality among breast cancer patients (Barron et al, 2011, Melhem-Bertrandt et al, 2011). However, as far as we are aware, no study has examined whether the use of $\beta$-blockers is associated with survival in EC.

The influence of inflammation (Modugno et al, 2005) and platelet interaction with tumour cells (Gay and FeldingHabermann, 2011) on the development of cancer has resulted in the suggestion that use of aspirin, a commonly prescribed antiplatelet medication, may be protective against EC development (Neill et al, 2013). In a recent multicentre retrospective study, which included 1687 women who underwent surgical staging for EC, low-dose aspirin users were reported to have improved disease-specific survival compared with non-users (hazard ratio (HR) 0.23 , 95\% confidence interval (CI) 0.08, 0.64) (Matsuo et al, 2016). In this study, medication use was not assessed over a long period of time and number of prescriptions was also not assessed. In addition, the study had a relatively short follow-up time.

Overall, there is a paucity of evidence from observational studies assessing the association between use of statins, $\beta$-blockers or lowdose aspirin and EC survival; there is a need for large populationbased studies to investigate whether EC patients would benefit from a protective effect of these drugs.

The aim of this population-based study was to assess the associations between post-diagnostic use of statins, $\beta$-blockers or aspirin and cancer-specific survival among newly diagnosed cases of EC

\section{MATERIALS AND METHODS}

Data sources. A large prospective cohort study utilising linkages between the UK Clinical Practice Research Datalink (CPRD, previously known as GPRD), the National Cancer Research Datalink (NCDR) and the Office of National Statistics (ONS) death registrations was conducted. The NCDR data contains information on all incident primary cancers in England, including date and site of cancer, tumour grade and stage, and cancerdirected treatment received. The CPRD is the world's largest computerised data set of anonymised longitudinal primary care records. It includes routinely collected high-quality data on patient demographics, clinical diagnoses and prescriptions in England (Jick et al, 1991, Boggon et al, 2013). Information on deaths was obtained from linkages to ONS mortality data including date and cause of death. Ethical approval for all observational studies conducted using CPRD data has been obtained from a multicentre research ethics committee.

Study design. Cases with an incident diagnosis of EC confirmed between January 1998 and December 2010 through cancer registry linkage were identified using ICD codes C54, C55 or 182. Cases with a previous NCDR-registered cancer diagnosis (excluding in situ neoplasms and non-melanoma skin cancers) were excluded. Cases were also excluded if their date of diagnosis preceded CPRD research quality records or if death registration records were unavailable. Cases who died within the first year after cancer diagnosis were also excluded (sensitivity analysis was conducted varying this interval), as it seemed unlikely that short term postdiagnostic medication usage could influence such deaths.

Cases were followed up from 1 year after EC diagnosis until death, end of registration with the general practice, last date of data collection from general practice (as patients would not have drug exposure data after this) or end of ONS follow-up (April 2014).

Exposure data. GP prescription data within the CPRD was used to determine post-diagnostic statins, $\beta$-blockers and low-dose aspirin use according to the British National Formulary (British Medical Association and the Royal Pharmaceutical Society of Great Britain: British National Formulary). Medications were treated as time-varying covariates, in order to avoid immortal time bias (Levesque et al, 2010). This bias relates to a length of time during which the outcome of interest may not occur, i.e., if the time from cohort entry to first exposure to a drug is improperly classified as 'exposed' when this time is actually 'immortal'. A lag of 6 months was applied to medication use, as recommended (Chubak et al, 2013 ), in order to exclude prescriptions received by patients in the 6 months before death (which may be due to changes due to endof-life treatment). Therefore, drug users were classified as nonusers until 6 months after first prescription and users thereafter. The number of prescriptions was used as proxy to represent 1 year of medication use (1-11 prescriptions) or more than 1 year use $(\geqslant 12$ prescriptions). Similarly, an individual was considered a non-user before 6 months after first medication usage, a short-term user from 6 months after first prescription to 6 months after the 12th prescription and a longer-term user after this time, excludes deaths in the first year after cancer diagnosis.

Covariates. Clinical information on EC stage and grade were taken from NCDR, in addition to data on cancer treatments (surgery, chemotherapy and radiotherapy) received within the 6 months after cancer diagnosis. Smoking, alcohol and body mass index (BMI) were derived from the most recent GP record within the 10 years before EC diagnosis. Comorbidities before EC diagnosis were extracted from GP-recorded clinical diagnoses and were based on the comorbidity codes included in a recent adaptation of the Charlson Comorbidity index for GPRD (Khan et al, 2010). A measure of socioeconomic status was obtained from deprivation measures within CPRD records which are based on residential postcodes (using the 2004 index of multiple deprivation for England) (Noble et al, 2004).

Data analysis. Cox regression models were used to derive HRs and 95\% CIs to assess post-diagnostic drug use and EC-specific mortality. Analyses were conducted based on number of prescriptions to assess potential dose-response relationships. Potential confounders were considered in adjusted models, including age and year of cancer diagnosis, treatment received within 6 months of cancer diagnosis (surgery, chemotherapy or radiotherapy), 
deprivation (in quintiles), comorbidities and medication use after diagnosis (statins, $\beta$-blockers and aspirin use, treated as timevarying covariates). All analyses were repeated for all-cause mortality.

As BMI is a well-known aetiological risk factor for EC, subgroup analyses were conducted stratifying by BMI status (BMI before diagnosis $\leqslant 25$ and $>25 \mathrm{~kg} \mathrm{~m}^{-2}$, respectively). Sensitivity analyses were conducted including additional adjustment for cancer stage (among individuals with available stage data) as a proportion $(\sim 50 \%)$ of our cohort had missing data for stage due to a lack of recording of cancer stage in some cancer registries. Drug exposure lag time was also increased to 1 year in sensitivity analysis. Further sensitivity analysis excluded patients with less than 6 months follow-up after diagnosis (as opposed to 1 year). Additional sensitivity analysis was conducted based upon drug prescriptions in the year before diagnosis, not excluding deaths in the first year after diagnosis with EC patients followed from diagnosis to death, end of registration with the general practice, last date of data collection from general practice or end of ONS followup. Cox regression models were used to calculate HRs and 95\% CIs for medication use based upon prescriptions in the year before diagnosis (restricted to individuals with at least 1 year of records before diagnosis). An adjusted analysis for pre-diagnostic statin use was also conducted, omitting stage, grade, cancer treatment from adjustments for potential confounders to avoid over-adjustment (Weinberg, 1993, Schisterman et al, 2009), as these could be on the causal pathway for EC-specific mortality.

\section{RESULTS}

Patient cohort. There were a total of 3646 EC cases identified between 1998 and 2010. A total of 588 of these were excluded due to having less than 1 year of follow-up after cancer diagnosis. This left 3058 cases, in whom 394 EC-specific deaths and 809 deaths from any cause occurred during a mean follow-up of 6.1 years (ranging from 1 to 16.3 years) (Supplementary Figure 1). Characteristics of all patients by statins, $\beta$-blockers and low-dose aspirin use are presented in Table 1.

Users of statins, $\beta$-blockers and/or low-dose aspirin were more likely to be older, overweight/obese and have a history of diabetes than non-users (Table 1). Statin and $\beta$-blocker (but not low-dose aspirin) users were slightly more likely to have consumed alcohol, compared with non-users (57-58\% vs 55\%, respectively). Of the three medication groups, only statin users were more likely to be diagnosed with early stage disease (stage $137 \%$ vs 32\%) and with well differentiated tumours (34\% vs 29\%) compared with nonusers. Statin and low-dose aspirin (but not $\beta$-blocker) users were more likely to be from deprived socio-economic backgrounds than non-users $(14 \%$ vs $10 \%)$. There appeared to be no marked difference between users of the three medication groups by smoking status before cancer diagnosis and type of cancer treatment received within 6 months of cancer diagnosis.

Statin users were more likely to use $\beta$-blockers and low-dose aspirin. Although users of $\beta$-blockers were more likely to use lowdose aspirin, they were less likely to use statin. A Kaplan-Meier survival curve was used to assess EC-specific survival by disease stage at diagnosis (Supplementary Figure 2). As expected, cancer stage at diagnosis was strongly associated with cancer-specific mortality.

Association between statin use after diagnosis and EC survival. Associations between statin use and EC survival are presented in Table 2. In the unadjusted model, there was little evidence of an association between post diagnostic statin use and EC-specific survival (HR 1.05, 95\% CI 0.83, 1.31). When relevant confounders were included in the model, no significant reduction in EC mortality was observed (adjusted HR 0.83, 95\% CI 0.64, 1.08). There appeared to be no evidence of a dose relationship between increasing number of statin prescriptions and EC-specific survival (Table 2). Similarly, null associations were observed between medication use and risk of all-cause death. Similar results were observed for pre-diagnostic use of statins and EC-specific or overall survival (Supplementary Table 1)

Association between $\beta$-blockers use after diagnosis and EC survival. Associations between $\beta$-blocker use and EC-specific survival are presented in Table 2 . In the unadjusted or adjusted models, there appeared to be limited evidence of an association between post-diagnostic use of $\beta$-blockers and EC-specific survival (unadjusted: HR 0.97, 95\% CI 0.77, 1.22; adjusted: HR 0.87, 95\% CI $0.68,1.10)$. There was also no evidence of a dose-response relationship between use of $\beta$-blockers and EC-specific survival (Table 2). There was no association between $\beta$-blockers use and allcause mortality (adjusted HR 1.04, 95\%CI 0.89, 1.22). There also appeared to be no significant association when pre-diagnostic use of $\beta$-blockers was assessed in relation to EC-specific or overall survival (Supplementary Table 1).

Association between low-dose aspirin use after diagnosis and EC survival. Associations between low-dose aspirin use and ECspecific survival are presented in Table 2 . In the unadjusted model, there appeared to be no significant association between postdiagnostic use of low-dose aspirin and EC-specific survival (unadjusted HR 1.14, 95\% CI 0.90, 1.44). After adjusting for confounders, the association between low-dose aspirin and EC survival remained nonsignificant (adjusted HR 0.91; 95\% CI 0.69, 1.20). There was also no evidence of a dose-response relationship between the use of low-dose aspirin and EC-specific survival (Table 2). There was no evidence of an association between the use of low-dose aspirin and death from any cause (Table 2). When we assessed pre-diagnostic use of low-dose aspirin, we found no significant associations for EC-specific or overall survival (Supplementary Table 1).

Sensitivity and sub-group analyses. Results from sensitivity/subgroup analyses are presented in Table 3 . In sub-group analysis, the previously observed null associations between use of statins, $\beta$ blockers or low-dose aspirin and EC-survival remained in stratified analysis by BMI category.

There was also no evidence of association between use of these drugs and EC survival after additionally adjusting for cancer stage (among individuals with available stage data) in sensitivity analyses or when the lag was increased to 1 year (Table 3 ).

\section{DISCUSSION}

The results from this UK population-based cohort study show no significant associations between post-diagnostic use of statins, $\beta$-blockers, and low-dose aspirin and EC survival. In addition, there was no evidence of a dose-response relationship with increasing number of prescriptions for EC survival and any of the drug groups studied.

Statins are thought to inhibit the melavonate pathway, thereby mitigating cancer cell growth and prevent the prenylation of the essential proteins involved in the migration and proliferation of cancer cell (Corcos, Le Jossic-corcos, 2013). Despite this proposed mechanism, the current study detected no significant association between statin use and EC survival. This is in line with, and builds upon, findings from a previous US cohort study that reported a slight nonsignificant reduced risk of death from any cause among statin users compared with non-users (Yoon et al, 2015).

However, other epidemiological studies have suggested a protective association between use of statin and overall or 
Table 1. Characteristics of endometrial cancer patients by statin, $\beta$-blocker and low-dose aspirin use after cancer diagnosis

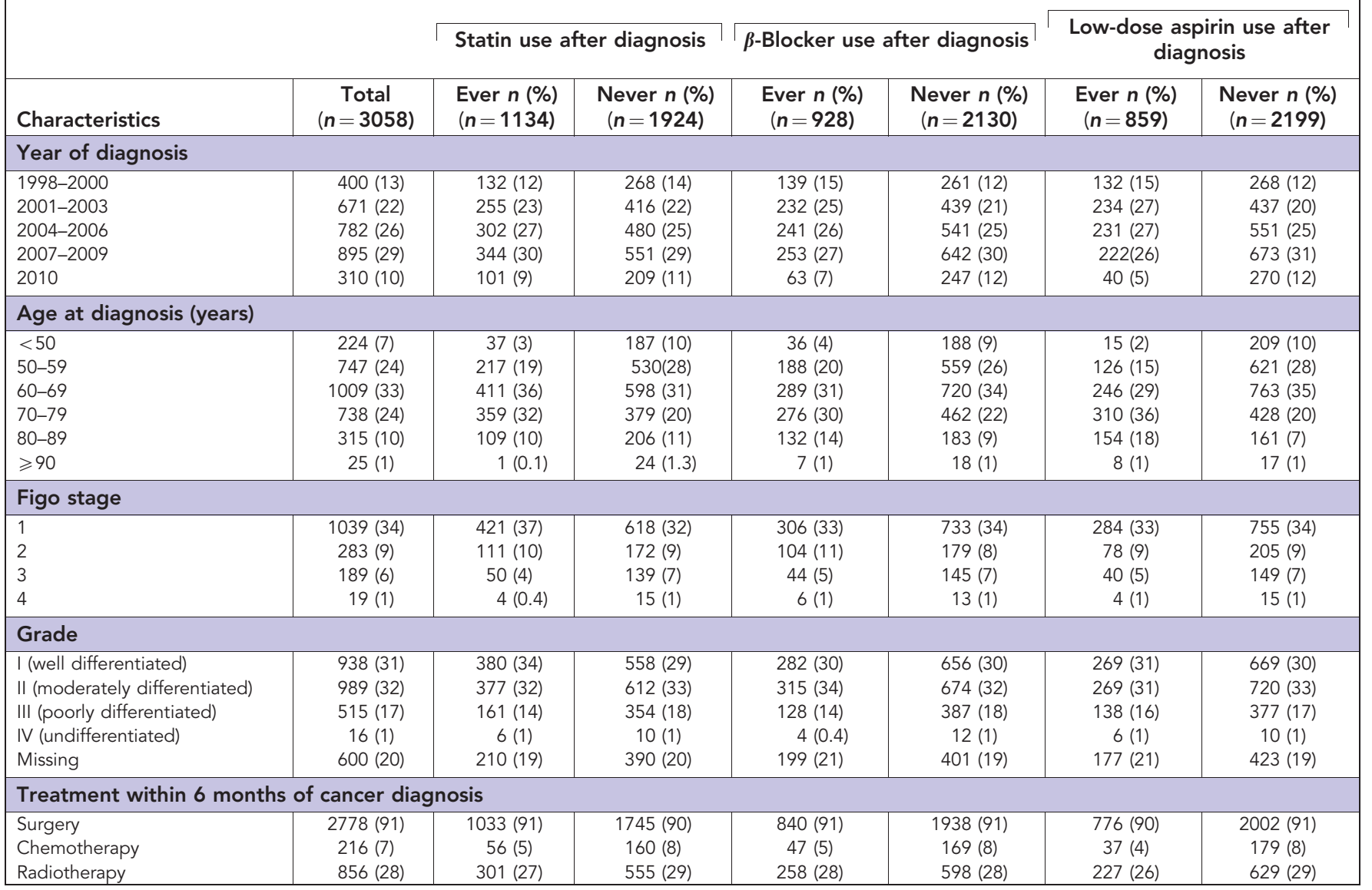

Table 2. Association between post-diagnostic statin, $\beta$-blockers and low-dose aspirin usage, and cancer-specific and all-cause mortality in endometrial patients

\begin{tabular}{|c|c|c|c|c|c|c|c|c|c|c|c|}
\hline \multirow[b]{2}{*}{ Medication usage after diagnosis } & \multicolumn{6}{|c|}{ Cancer-specific mortality } & \multicolumn{5}{|c|}{ All-cause mortality } \\
\hline & $\begin{array}{l}\text { Cancer- } \\
\text { specific } \\
\text { deaths }\end{array}$ & $\begin{array}{c}\text { All } \\
\text { patients }\end{array}$ & $\begin{array}{l}\text { Unadjusted HR } \\
\quad(95 \% \mathrm{Cl})\end{array}$ & $P$ & $\begin{array}{l}\text { Adjusted }^{a} \text { HR } \\
\quad(95 \% \mathrm{Cl})\end{array}$ & $P$ & $\begin{array}{c}\text { All- } \\
\text { cause } \\
\text { deaths }\end{array}$ & $\begin{array}{l}\text { Unadjusted HR } \\
(95 \% \mathrm{Cl})\end{array}$ & $P$ & $\begin{array}{l}\text { Adjusted }^{a} \\
\text { HR }(95 \% \mathrm{Cl})\end{array}$ & $P$ \\
\hline \multicolumn{12}{|l|}{ Statins } \\
\hline Statin non-user & 288 & 1924 & 1.00 & & 1.00 & & 542 & 1.00 & & 1.00 & \\
\hline Statin user $^{\mathbf{b}}$ & 106 & 1134 & $1.05(0.83,1.31)$ & 0.67 & $0.83(0.64,1.08)$ & 0.07 & 267 & $1.26(1.08,1.46)$ & 0.003 & $0.91(0.77,1.09)$ & 0.32 \\
\hline Statin non-user & 288 & 1924 & 1.00 & & 1.00 & & 542 & 1.00 & & 1.00 & \\
\hline Statin use $1-11$ prescriptions $^{c}$ & 53 & 291 & $1.09(0.81,1.46)$ & 0.58 & $0.88(0.64,1.22)$ & 0.44 & 111 & $1.26(1.03,1.55)$ & 0.03 & $0.97(0.77,1.21)$ & 0.79 \\
\hline Statin use $\geqslant 12$ prescriptions ${ }^{c}$ & 53 & 843 & $1.01(0.75,1.37)$ & 0.94 & $0.78(0.55,1.10)$ & 0.16 & 156 & $1.25(1.04,1.50)$ & 0.02 & $0.87(0.70,1.08)$ & 0.20 \\
\hline \multicolumn{12}{|l|}{$\beta$-blockers } \\
\hline$\beta$-blocker non-user & 295 & 2130 & 1.00 & & 1.00 & & 543 & 1.00 & & 1.00 & \\
\hline$\beta$-blocker user ${ }^{\mathrm{b}}$ & 99 & 928 & $0.97(0.77,1.22)$ & 0.77 & $0.87(0.68,1.10)$ & 0.24 & 266 & $1.31(1.13,1.53)$ & $<0.0001$ & $1.04(0.89,1.22)$ & 0.60 \\
\hline$\beta$-blocker non-user & 295 & 2130 & 1.00 & & 1.00 & & 543 & 1.00 & & 1.00 & \\
\hline$\beta$-blocker use 1-11 prescriptions ${ }^{c}$ & 50 & 279 & $1.01(0.74,1.36)$ & 0.97 & $0.93(0.68,1.27)$ & 0.65 & 102 & $1.19(0.96,1.47)$ & 0.12 & $1.01(0.81,1.26)$ & 0.91 \\
\hline$\beta$-blocker use $\geqslant 12$ prescriptions ${ }^{c}$ & 49 & 649 & $0.93(0.68,1.27)$ & 0.65 & $0.80(0.58,1.11)$ & 0.18 & 164 & $1.42(1.19,1.70)$ & $<0.0001$ & $1.06(0.88,1.29)$ & 0.52 \\
\hline \multicolumn{12}{|l|}{ Low-dose aspirin } \\
\hline Low-dose aspirin non-user & 304 & 2199 & 1.00 & & 1.00 & 547 & 1.00 & 1.00 & & & \\
\hline Low-dose aspirin user $^{\text {b }}$ & 90 & 859 & $1.14(0.90,1.44)$ & 0.28 & $0.91(0.69,1.20)$ & 0.52 & 262 & $1.66(1.43,1.93)$ & $<0.001$ & $1.10(0.92,1.31)$ & 0.28 \\
\hline Low-dose aspirin non-user & 304 & 2199 & 1.00 & & 1.00 & 547 & 1.00 & 1.00 & & & \\
\hline Low-dose aspirin use $1-11$ prescriptions ${ }^{c}$ & 54 & 325 & $1.17(0.87,1.56)$ & 0.30 & $0.95(0.69,1.31)$ & 0.76 & 120 & $1.45(1.19,1.77)$ & $<0.001$ & $1.00(0.81,1.25)$ & 0.94 \\
\hline Low-dose aspirin use $\geqslant 12$ prescriptions ${ }^{c}$ & 36 & 534 & $1.10(0.77,1.57)$ & 0.60 & $0.85(0.58,1.26)$ & 0.72 & 142 & $1.92(1.58,2.32)$ & $<0.001$ & $1.21(0.98,1.50)$ & 0.08 \\
\hline \multicolumn{12}{|c|}{$\begin{array}{l}\text { Abbreviations: } \mathrm{Cl}=\text { confidence interval; } \mathrm{HR}=\text { hazard ratio. } \\
{ }^{\mathrm{a}} \text { Adjusted for year of diagnosis, age at diagnosis, surgery within } 6 \text { months, radiotherapy within } 6 \text { months, chemotherapy within } 6 \text { months, deprivation (in fifths), comorbidities (before diagnosis, } \\
\text { including cerebrovascular disease, chronic pulmonary disease, congestive heart disease, diabetes, myocardial infarction, peptic ulcer disease, peripheral vascular disease and renal disease), } \\
\text { medication use after diagnosis (time varying, including statins, } \beta \text {-blockers and low-dose aspirin). } \\
{ }^{b} \text { Medication use modelled as a time-varying covariate. An individual was considered a non-user before } 6 \text { months after first medication usage and a user after this time, excludes deaths in the } 1 \\
\text { year after cancer diagnosis. } \\
{ }^{c} \text { Medication use modelled as a time varying covariate. An individual was considered a nonuser before } 6 \text { months after first medication usage, a short-term user from } 6 \text { months after first } \\
\text { prescription to } 6 \text { months after the 12th prescription and a longer-term user after this time, excludes deaths in the first year after cancer diagnosis. }\end{array}$} \\
\hline
\end{tabular}


Table 3. Sensitivity analyses for association between statins, $\beta$-blockers and low-dose aspirin use and cancer-specific mortality in endometrial cancer patients

\begin{tabular}{|c|c|c|c|c|c|}
\hline Analysis & $\begin{array}{c}\text { Cancer-specific } \\
\text { deaths }\end{array}$ & All patients & Person years & $\begin{array}{c}\text { Adjusted }{ }^{\mathrm{a}} \mathrm{HR} \\
(95 \% \mathrm{Cl})\end{array}$ & $P$ \\
\hline \multicolumn{6}{|l|}{ Statins } \\
\hline Main analysis: user vs non-user after diagnosis & 394 & 3058 & 15653 & $0.83(0.64,1.08)$ & 0.07 \\
\hline $\begin{array}{l}\text { Sub group analyses: user vs non-user after diagnosis, restricted to } \\
\text { BMI before diagnosis, } \leqslant 25 \mathrm{~kg} \mathrm{~m}^{-2} \\
\text { BMI before diagnosis, } 25-<30 \mathrm{~kg} \mathrm{~m}^{-2} \\
\text { BMI before diagnosis, }>30 \mathrm{~kg} \mathrm{~m}^{-2}\end{array}$ & $\begin{array}{r}68 \\
97 \\
141\end{array}$ & $\begin{array}{r}545 \\
726 \\
1144\end{array}$ & $\begin{array}{l}2970 \\
3730 \\
5606\end{array}$ & $\begin{array}{l}0.75(0.36,1.58) \\
0.80(0.47,1.39) \\
0.97(0.63,1.49)\end{array}$ & $\begin{array}{l}0.46 \\
0.43 \\
0.89\end{array}$ \\
\hline $\begin{array}{l}\text { Sensitivity analyses: user vs non-user after diagnosis } \\
\text { Stage at diagnosis available (and adjusted for })^{\text {b }} \\
\text { Increasing lag to } 1 \text { year } \\
\text { Excluding patients with } \leqslant 6 \text { months follow-up after diagnosis }\end{array}$ & $\begin{array}{l}163 \\
394 \\
523\end{array}$ & $\begin{array}{l}1530 \\
3058 \\
3306\end{array}$ & $\begin{array}{r}7281 \\
15653 \\
17249\end{array}$ & $\begin{array}{l}0.98(0.67,1.46) \\
0.88(0.67,1.16) \\
0.88(0.69,1.11)\end{array}$ & $\begin{array}{l}0.96 \\
0.36 \\
0.28\end{array}$ \\
\hline \multicolumn{6}{|l|}{$\beta$-Blockers } \\
\hline Main analysis: user vs non-user after diagnosis & 394 & 3058 & 15653 & $0.87(0.68,1.10)$ & 0.24 \\
\hline $\begin{array}{l}\text { Sub group analyses: user vs non-user after diagnosis, restricted to } \\
\text { BMI before diagnosis, } \leqslant 25 \mathrm{~kg} \mathrm{~m}^{-2} \\
\text { BMI before diagnosis, } 25-<30 \mathrm{~kg} \mathrm{~m}^{-2} \\
\text { BMI before diagnosis, }>30 \mathrm{~kg} \mathrm{~m}^{-2}\end{array}$ & $\begin{array}{r}68 \\
97 \\
141\end{array}$ & $\begin{array}{r}545 \\
726 \\
1144\end{array}$ & $\begin{array}{l}2970 \\
3730 \\
5606\end{array}$ & $\begin{array}{l}0.97(0.48,1.94) \\
1.16(0.72,1.87) \\
0.69(0.45,1.04)\end{array}$ & $\begin{array}{l}0.93 \\
0.55 \\
0.07\end{array}$ \\
\hline $\begin{array}{l}\text { Sensitivity analyses: user vs non-user after diagnosis } \\
\text { Stage at diagnosis available (and adjusted for) }{ }^{\mathrm{b}} \\
\text { Increasing lag to } 1 \text { year }^{c} \\
\text { Excluding patients with } \leqslant 6 \text { months follow-up after diagnosis }\end{array}$ & $\begin{array}{l}163 \\
394 \\
523\end{array}$ & $\begin{array}{l}1530 \\
3058 \\
3306\end{array}$ & $\begin{array}{r}7281 \\
15653 \\
17249\end{array}$ & $\begin{array}{l}0.88(0.60,1.29) \\
0.91(0.71,1.16) \\
0.83(0.67,1.03)\end{array}$ & $\begin{array}{l}0.51 \\
0.43 \\
0.10\end{array}$ \\
\hline \multicolumn{6}{|l|}{ Low-dose aspirin } \\
\hline Main analysis: user vs non-user after diagnosis & 394 & 3058 & 15653 & $0.91(0.69,1.20)$ & 0.52 \\
\hline $\begin{array}{l}\text { Sub group analyses: user vs non-user after diagnosis, restricted to } \\
\text { BMI before diagnosis, } \leqslant 25 \mathrm{~kg} \mathrm{~m}^{-2} \\
\text { BMI before diagnosis, } 25-<30 \mathrm{~kg} \mathrm{~m}^{-2} \\
\text { BMI before diagnosis, }>30 \mathrm{~kg} \mathrm{~m}^{-2}\end{array}$ & $\begin{array}{r}68 \\
97 \\
141\end{array}$ & $\begin{array}{r}545 \\
726 \\
1144\end{array}$ & $\begin{array}{l}2970 \\
3730 \\
5606\end{array}$ & $\begin{array}{l}0.95(0.47,1.89) \\
0.62(0.33,1.16) \\
0.75(0.47,1.21)\end{array}$ & $\begin{array}{l}0.88 \\
0.13 \\
0.24\end{array}$ \\
\hline $\begin{array}{l}\text { Sensitivity analyses: user vs non-user after diagnosis } \\
\text { Stage at diagnosis available (and adjusted for })^{\text {b }} \\
\text { Increasing lag to } 1 \text { year } \\
\text { Excluding patients with } \leqslant 6 \text { months follow-up after diagnosis } \\
\end{array}$ & $\begin{array}{l}163 \\
394 \\
523 \\
\end{array}$ & $\begin{array}{l}1530 \\
3058 \\
3306 \\
\end{array}$ & $\begin{array}{r}7281 \\
15653 \\
17249 \\
\end{array}$ & $\begin{array}{l}0.93(0.61,1.41) \\
0.90(0.68,1.20) \\
0.98(0.77,1.25)\end{array}$ & $\begin{array}{l}0.72 \\
0.47 \\
0.90\end{array}$ \\
\hline \multicolumn{6}{|c|}{$\begin{array}{l}\text { Abbreviations: } \mathrm{BMI}=\text { body mass index; } \mathrm{Cl}=\text { confidence interval; } \mathrm{HR}=\text { hazard ratio. } \\
\text { a Adjusted for year of diagnosis, age at diagnosis, surgery within } 6 \text { months, radiotherapy within } 6 \text { months, chemotherapy within } 6 \text { months, deprivation (in fifths), comorbidities (before diagnosis, } \\
\text { including cerebrovascular disease, chronic pulmonary disease, congestive heart disease, diabetes, myocardial infarction, peptic ulcer disease, peripheral vascular disease and renal disease), } \\
\text { medication use after diagnosis (time varying, including statins, } \beta \text {-blockers and low-dose aspirin). } \\
\text { b }_{\text {Adjusted model contains all variables in a along with stage at diagnosis (in individuals with stage available). }} \\
c_{\text {Increasing lag to } 1 \text { year among individuals living more than } 1 \text { year after cancer diagnosis. }} \\
d_{\text {Excluding patients with } \leq 6 \text { months follow-up after diagnosis with cases followed from } 6 \text { months after diagnosis }}\end{array}$} \\
\hline
\end{tabular}

disease-free survival in EC cases (Lavie et al, 2013, Nevadunsky et al, 2015). In the CITOUS study conducted in Israel, Lavie et al (2013) reported an association between statin use and reduced risk of death from any cause (HR 0.35, 95\% CI 0.12, 0.96). However, that study included a relatively small sample of cases from a single institution and there was also potential for immortal time bias as drug use was not treated as a time-dependent variable. This bias relates to a length of time during which the outcome of interest may not occur, i.e., if the time from cohort entry to first exposure to a drug is improperly classified as 'exposed' when this time is actually 'immortal' (in that an individual has to be alive in order to be classed as exposed). Our analysis avoided this particular bias by treating all drug exposures as time-varying covariates. In another US retrospective cohort study including 985 EC cases, Nevadunsky et al (2015) reported improved disease-free survival among statin users compared with non-users. However, this was also a single institution study and, importantly, only one exposure time point (statin use at diagnosis only) was used to determine drug use (Nevadunsky et al, 2015), whereas in the current study, medication use was assessed over an extended time period and by number of prescriptions.

This is the first study to assess the relationship between the use of $\beta$-blockers and EC-specific mortality. Previous studies have suggested that pre- (Powe et al, 2010, Barron et al, 2011) and post-diagnostic (Melhem-Bertrandt et al, 2011, Cardwell et al, 2013) $\beta$-blockers use may have a part in reduction of tumour occurrence, metastasis and cancer-specific mortality among breast cancer patients (Powe et al, 2010, Barron et al, 2011, Cardwell et al, 2013). A recent retrospective multi-centric study concluded that the use of any type of $\beta$-blocker resulted in improved diseasespecific survival during the first year following diagnosis among women with epithelial ovarian cancer (Watkins et al, 2015). This is consistent with preclinical studies that have shown the activation of adrenergic receptors results in the growth and progression of ovarian cancer (Watkins et al, 2015). However, extrapolation of these mechanisms to EC may not be applicable, as there was no evidence of an association between use of $\beta$-blockers and EC survival in this study.

In a recent multicentre study, Matsuo et al (2016) reported a significant association between the use of low-dose aspirin and EC survival. In the study, users of low-dose aspirin were reported to have improved disease-specific survival compared with non-users (HR 0.23 95\% CI 0.08, 0.64) (Matsuo et al, 2016). However, medication use was not assessed over an extended time period, it was determined only at diagnosis. Furthermore, the authors were unable to assess frequency of drug use and follow-up period for the study was relatively short (median 31.5 months), whereas in the current study with a mean follow-up period of 6.1 years and 
information on number of prescriptions was available and included in analyses. Earlier studies have shown that tumour cells interact with platelets and platelets including platelet activation have been linked to key steps in cancer progression (Bambace and Holmes, 2011, Gay and Felding-Habermann, 2011). Although post diagnostic the use of aspirin has also been linked to a reduced risk of cancer-specific mortality or recurrence in prostate (Choe et al, 2012), breast (Kwan et al, 2007, Holmes et al, 2010) and colorectal cancer (Liao et al, 2012, $\mathrm{Ng}$ et al, 2014) patients, there was no evidence of an association between use of low-dose aspirin and EC survival in the current study.

This study has several strengths. It is the first study to examine the associations between the use of $\beta$-blockers after diagnosis in relation to EC survival. Our cohort of EC patients represents the largest to date to assess the association between statin or low-dose aspirin use and EC survival. Linkage of NCDR and ONS enabled robust verification of EC cases and deaths. GP prescription records also allowed adequate measure of drug exposure including type, dose and timing of use. Importantly, we regarded drug use as time-dependent covariates in order to avoid immortal time bias. The study also benefitted from a relatively long follow-up period of up to 16 years.

There are some limitations of this study to consider. We did not have information on low-dose aspirin sold over-the-counter (OTC), although previous investigation within the GPRD has found that the majority of chronic aspirin use was captured by prescription records (Yang et al, 2008). Misclassification of statin use is also possible due to OTC use, but only low-dose $10 \mathrm{mg}$ simvastatin is available OTC in the United Kingdom and only from 2004 (Stewart et al, 2010); therefore, the risk of bias due to drug misclassification is greatly reduced. Furthermore, missing OTC drug exposure has previously been shown not to be a large source of bias when estimating drug-disease association (Yood et al, 2007). A proportion of our cohort had missing data for tumour stage $(50 \%)$, which reduced the number of patients included in our stage-adjusted model and could therefore potentially result in some residual confounding. However, results from sensitivity analysis, which additionally adjusted for stage, were similar to the main analysis. A limitation of this study was our inability to perform stratified analysis by histological type, although the majority of EC cases are Type I and survival is generally better for this group of patients compared with those with Type II disease (Morice et al, 2016). One previous study indicated that a beneficial effect of statins may exist for Type II EC only (Nevadunsky et al, 2015); however, a subsequent report saw no difference in survival for statin users between older patients with Type I and II tumours (Yoon et al, 2015). Recent advances have also been made in our knowledge of molecular subtypes of EC, with the 2013 Integrated Genomic consortium classifying tumours into four categories that have distinct prognoses (Cancer Genome Atlas Research Network, 2013). It is therefore a limitation of this study that we are unable to investigate our associations by molecular subtypes and future molecular pathology epidemiology studies may be warranted.

In conclusion, the findings from this large population-based study suggested no associations between post-diagnostic use of statins, $\beta$-blockers or low-dose aspirins and EC-specific mortality. Considering that this study is the first to assess the influence of $\beta$-blockers use and EC survival, the inconsistent and very limited findings from previous studies of statin or low-dose aspirin use and overall survival, further high-quality studies are warranted.

\section{ACKNOWLEDGEMENTS}

OS is being funded by a QUB International $\mathrm{PhD}$ studentship. OS, $\mathrm{UMcM}, \mathrm{LJM}$ and HGC are affiliates or co-investigators of the UKCRC Centre of Excellence for Public Health NI. The acquisition of the data for this study was funded by a grant from the Health Research Board (HRA/2012/30). This study is based in part on data from the Clinical Practice Research Data link obtained under licence from the UK Medicines and Healthcare products Regulatory Agency. However, the interpretation and conclusions contained in this study are those of the author/s alone.

\section{CONFLICT OF INTEREST}

The authors declare no conflict of interest.

\section{REFERENCES}

Aronow WS (2010) Current role of beta-blockers in the treatment of hypertension. Expert Opin Pharmacother 11(16): 2599-2607.

Bambace N, Holmes C (2011) The platelet contribution to cancer progression. J Thromb Haemost 9(2): 237-249.

Barron TI, Connolly RM, Sharp L, Bennett K, Visvanathan K (2011) Beta blockers and breast cancer mortality: a population- based study. J Clin Oncol 29(19): 2635-2644.

Boggon R, Staa TP, Chapman M, Gallagher AM, Hammad TA, Richards MA (2013) Cancer recording and mortality in the General Practice Research Database and linked cancer registries. Pharmacoepidemiol Drug Safety 22(2): 168-175.

Cancer Genome Atlas Research Network (2013) Integrated genomic characterization of endometrial carcinoma. Nature 497(7447): 67-73.

Cardwell CR, Coleman HG, Murray LJ, Entschladen F, Powe DG (2013) Betablocker usage and breast cancer survival: a nested case-control study within a UK Clinical Practice Research Datalink cohort. Int J Epidemiol 42(6): 1852-1861.

Choe KS, Cowan JE, Chan JM, Carroll PR, D'Amico AV, Liauw SL (2012) Aspirin use and the risk of prostate cancer mortality in men treated with prostatectomy or radiotherapy. J Clin Ocol 30(28): 3540-3544.

Chubak J, Boudreau DM, Wirtz HS, McKnight B, Weiss NS (2013) Threats to validity of nonrandomized studies of postdiagnosis exposures on cancer recurrence and survival. J Natl Cancer Inst 105(19): 1456-1462.

Corcos L, Le Jossic-corcos C (2013) Statins: perspectives in cancer therapeutics. Dig Liver Dis 45(10): 795-802.

Dossus L, Allen N, Kaaks R, Bakken K, Lund E, Tjonneland A, Olsen A, Overvad K, Clavel-Chapelon F, Fournier A (2010) Reproductive risk factors and endometrial cancer: the European Prospective Investigation into Cancer and Nutrition. Int J Cancer 127(2): 442-451.

Ferlay J, Soerjomataram I, Dikshit R, Eser S, Mathers C, Rebelo M, Parkin DM, Forman D, Bray F (2015) Cancer incidence and mortality worldwide: sources, methods and major patterns in GLOBOCAN 2012. Int J Cancer 136(5): E359-E386.

Gao J, Niwa K, Sun W, Takemura M, Lian Z, Onogi K, Seishima M, Mori H, Tamaya T (2004) Non-steroidal anti-inflammatory drugs inhibit cellular proliferation and upregulate cyclooxygenase-2 protein expression in endometrial cancer cells. Cancer Sci 95(11): 901-907.

Gay LJ, Felding-Habermann B (2011) Contribution of platelets to tumour metastasis. Nat Rev Cancer 11(2): 123-134.

Gupta SC, Sung B, Prasad S, Webb LJ, Aggarwal BB (2013) Cancer drug discovery by repurposing: teaching new tricks to old dogs. Trends Pharmacol Sci 34(9): 508-517.

Holmes MD, Chen WY, Li L, Hertzmark E, Spiegelman D, Hankinson SE (2010) Aspirin intake and survival after breast cancer. J Clin Oncol 28(9): 1467-1472.

Jick H, Jick SS, Derby LE (1991) Validation of information recorded on general practitioner based computerised data resource in the United Kingdom. BMJ 302(6779): 766-768.

Khan NF, Perera R, Harper S, Rose PW (2010) Adaptation and validation of the Charlson Index for Read/OXMIS coded databases. BMC Fam Pract 11: 1 .

Kwan ML, Habel LA, Slattery ML, Caan B (2007) NSAIDs and breast cancer recurrence in a prospective cohort study. Cancer Causes Control 18(6): 613-620.

Lavie O, Pinchev M, Rennert HS, Segev Y, Rennert G (2013) The effect of statins on risk and survival of gynecological malignancies. Gynecol Oncol 130(3): 615-619. 
Levesque LE, Hanley JA, Kezouh A, Suissa S (2010) Problem of immortal time bias in cohort studies: example using statins for preventing progression of diabetes. BMJ 340: b5087.

Liao X, Lochhead P, Nishihara R, Morikawa T, Kuchiba A, Yamauchi M, Imamura Y, Qian ZR, Baba Y, Shima K (2012) Aspirin use, tumor PIK3CA mutation, and colorectal-cancer survival. N Engl J Med 367(17): 1596-1606.

Matsuo K, Cahoon SS, Yoshihara K, Shida M, Kakuda M, Adachi S, Moeini A, Machida H, Garcia-Sayre J, Ueda Y, Enomoto T (2016) Association of low-dose aspirin and survival of women with endometrial cancer. Obstet Gynecol 128(1): 127-137.

Melhem-Bertrandt A, Chavez-Macgregor M, Lei X, Brown EN, Lee RT, Meric-Bernstam F, Sood AK, Conzen SD, Hortobagyi GN, Gonzalez-Angulo AM (2011) Beta-blocker use is associated with improved relapse-free survival in patients with triple-negative breast cancer. J Clin Oncol 29(19): 2645-2652.

Modugno F, Ness RB, Chen C, Weiss NS (2005) Inflammation and endometrial cancer: a hypothesis. Cancer Epidemiol Biomarkers Prev 14(12): 2840-2847.

Morice P, Leary A, Creutzberg C, Abu-Rustum N, Darai E (2016) Endometrial cancer. The Lancet 387(10023): 1094-1108.

Neill AS, Nagle CM, Protani MM, Obermair A, Spurdle AB, Webb PM (2013) Aspirin, nonsteroidal anti-inflammatory drugs, paracetamol and risk of endometrial cancer: a case-control study, systematic review and metaanalysis. Int J Cancer 132(5): 1146-1155.

Nevadunsky NS, Van Arsdale A, Strickler HD, Spoozak LA, Moadel A, Kaur G, Girda E, Goldberg GL, Einstein MH (2015) Association between statin use and endometrial cancer survival. Obstet Gynecol 126(1): 144-150.

Ng K, Meyerhardt JA, Chan AT, Sato K, Chan JA, Niedzwiecki D, Saltz LB, Mayer RJ, Benson 3rd AB, Schaefer PL, Whittom R, Hantel A, Goldberg RM, Venook AP, Ogino S, Giovannucci EL, Fuchs CS (2014) Aspirin and COX-2 inhibitor use in patients with stage III colon cancer. J Natl Cancer Inst 107(1): 345.

Noble M, Wright G, Dibben C, Smith G, McLennan D, Anttila C, Barnes H, Mokhtar C, Noble S, Avenell D, Gardner J, Covizzi I, Lloyd M (2004) Indices of deprivation 2004: Report to the office of the deputy prime minister. London, UK.

Powe DG, Voss MJ, Zänker KS, Habashy HO, Green AR, Ellis IO, Entschladen F (2010) Beta-blocker drug therapy reduces secondary cancer formation in breast cancer and improves cancer specific survival. Oncotarget 1(7): 628-638.
Rutishauser J (2011) Statins in clinical medicine. Swiss Med Wkly 141: w13310.

Schisterman EF, Cole SR, Platt RW (2009) Overadjustment bias and unnecessary adjustment in epidemiologic studies. Epidemiology 20(4): 488-495.

Schointuch MN, Gilliam TP, Stine JE, Han X, Zhou C, Gehrig PA, Kim K, Bae-Jump VL (2014) Simvastatin, an HMG-CoA reductase inhibitor, exhibits anti-metastatic and anti-tumorigenic effects in endometrial cancer. Gynecol Oncol 134(2): 346-355.

Siegel RL, Miller KD, Jemal A (2015) Cancer statistics, 2015. Cancer J Clin 65(1): 5-29.

Stewart D, Cunningham I, Hansford D, John D, McCaig D, McLay J (2010) General practitioners' views and experiences of over-the-counter simvastatin in Scotland. Br J Clin Pharmacol 70(3): 356-359.

Thibault A, Samid D, Tompkins AC, Figg WD, Cooper MR, Hohl RJ, Trepel J, Liang B, Patronas N, Venzon DJ, Reed E, Myers CE (1996) Phase I study of lovastatin, an inhibitor of the mevalonate pathway, in patients with cancer. Clin Cancer Res 2(3): 483-491.

Watkins JL, Thaker PH, Nick AM, Ramondetta LM, Kumar S, Urbauer DL, Matsuo K, Squires KC, Coleman RL, Lutgendorf SK (2015) Clinical impact of selective and nonselective beta-blockers on survival in patients with ovarian cancer. Cancer 121(19): 3444-3451.

Weinberg CR (1993) Toward a clearer definition of confounding. Am J Epidemiol 137(1): 1-8.

Yang Y, Pharmd S, Propert K, Hwang W, Sarkar M, Lewis J (2008) Chronic statin therapy and the risk of colorectal cancer. Pharmacoepidemiol Drug Saf 17(9): 869-876.

Yood MU, Campbell UB, Rothman KJ, Jick SS, Lang J, Wells KE, Jick H, Johnson CC (2007) Using prescription claims data for drugs available over-the-counter (OTC). Pharmacoepidemiol Drug Saf 16(9): 961-968.

Yoon LS, Goodman MT, Rimel B, Jeon CY (2015) Statin use and survival in elderly patients with endometrial cancer. Gynecol Oncol 137(2): 252-257.

This work is published under the standard license to publish agreement. After 12 months the work will become freely available and the license terms will switch to a Creative Commons AttributionNonCommercial-Share Alike 4.0 Unported License.

Supplementary Information accompanies this paper on British Journal of Cancer website (http://www.nature.com/bjc) 